\title{
POLYPEPTIDE \\ COMPOSITION OF INTERNAL MEMBRANES FROM BARLEY ETIOPLASTS
}

\author{
by \\ G. HØYER-HANSEN \\ Department of Physiology, Carlsberg Laboratory \\ Gamle Carlsberg Vej 10 - DK-2500 Copenhagen, Valby \\ O. MACHOLD ${ }^{1}$ \\ Zentralinstitut für Genetik und Kulturpflanzenforschung \\ der Akademie der Wissenschaften der DDR, Gatersleben G.D.R. \\ A. KAHN \\ Institute of Genetics, University of Copenhagen \\ Øster Farimagsgade 2A, DK-1353 Copenhagen, Denmark \\ ${ }^{1}$ Recipient of a Danish State Scholarship 1975 for stay at the Institute of Genetics, University of Copenhagen, \\ where this work was performed \\ Key words: chlorophyll-protein complexes, chloroplast membranes, SDS-gel electrophoresis \\ The polypeptides of isolated etioplast membranes and chloroplast membranes were solubilized in sodium \\ dodecyl sulfate. Protein band patterns were obtained by electrophoresis on polyacrylamide slab gels with \\ separating gels containing either a uniform polyacrylamide concentration or a concentration gradient. Several \\ characteristic chloroplast bands were absent or reduced in intensity in patterns of etioplast membranes. Con- \\ versely, certain bands found in etioplast membrane patterns were reduced or absent in patterns of chloroplast \\ membranes. Among these was a distinct doublet detected only in patterns of etioplast membrane polypeptides \\ obtained with gels lacking urea. Some bands, for example those tentatively identified as subunits of coupling \\ factor were found in patterns of etioplast as well as chloroplast membranes.
}

\section{INTRODUCTION}

In algae the formation of photosynthetic membranes involves the synthesis of specific chloroplast membrane polypeptides $(2,6,7$,
11). Likewise in higher plants the development of the chloroplast from the etioplast of darkgrown seedlings is accompanied by the synthesis of membrane polypetides, some of which 
are minor components or not detectable in etioplast membranes $(5,9,10,17,18)$. The relatively large number of polypeptides associated with photosynthetic membranes makes detailed comparisons between different developmental stages or between species a cumbersome task. Furthermore, the function of the polypeptides is frequently lost as a result of the solubilization of the membrane. Therefore, the characterization of the polypeptides is carried out by determination of relative electrophoretic mobility and by use of non-covalently bound markers such as chlorophyll associated with certain proteins. These characteristics vary with the procedure employed. Mutants in which one or a few membrane polypeptides are strongly reduced in amounts or missing as well as mutants containing new polypeptides are powerful tools in helping to characterize the membrane proteins and their function (e.g. 1, 3, 4, 15, 16, 17).

Previous work on the characterization of the lamellar proteins of barley chloroplast mutants in the Copenhagen stock collection was carried out by membrane solubilization with phenolacetic acid-urea and based on an analysis of chloroplast membrane development during greening of etioplasts in wild type barley (17). In the present paper we report on a comparison of barley etioplast membrane polypeptides with those of fully developed chloroplast membranes using sodium dodecyl sulfate for membrane solubilization and various conditions for electrophoresis. In agreement with earlier studies it can be shown, that some chloroplast membrane polypeptides are not detectable in etioplast membranes. Conversely, it is also found, that certain prominent polypeptides of etioplast membrane preparations are minor components or absent in chloroplast membrane preparations.

\section{MATERIALS AND METHODS}

\subsection{Plant Material}

Barley seedlings (Hordeum vulgare $\mathrm{L} \mathrm{cv}$. Svalöfs Bonus) were grown on tap water moistened vermiculite in darkness at $23^{\circ} \mathrm{C}$ for 7 days to provide material for etioplast isolation. For chloroplast isolation seedlings were grown for 5 days in darkness at $23^{\circ} \mathrm{C}$ followed by two days in continous light $(1500 \operatorname{lux})$ at $22^{\circ} \mathrm{C}$. Green safe-light was used when necessary for vision during growth of the plants and the isolation of etioplasts.

\subsection{Plastid Isolation and Preparation of Membranes}

The apical $5 \mathrm{~cm}$ segments of the primary leaves were harvested, and all subsequent operations were performed af 0 til $4^{\circ} \mathrm{C}$, until the plastid membranes were solubilized. Thirty to $45 \mathrm{~g}$ of leaf material were cut into approximately $1 \mathrm{~cm}$ pieces and ground with $4.5 \mathrm{ml}$. of grinding medium $(0.10 \mathrm{M}$ tricine- $\mathrm{NaOH}, 0.20 \mathrm{M}$ sucrose, $4 \mathrm{mM} \mathrm{MgCl}, 10 \mathrm{mM} \mathrm{KCl}$, and $5 \mathrm{mM}$ dithiothreitol at $\mathrm{pH} 7.5$ ) per $\mathrm{g}$ of leaves, using three 10 second bursts of a Sorvall Omnimixer at setting 7.5 with stirring between bursts. An additional batch of leaf material was ground in the same way, when a greater yield of plastids was desired.

The homogenate was filtered through Miracloth backed by $30 \mu \mathrm{m}$ mesh gauze and centrifuged for 10 minutes at $2000 \mathrm{rpm}(480$, maximum R.C.F.) in a Sorvall SS34 rotor. Subsequent centrifugations were done with the same rotor, unless stated otherwise. The supernatant was discarded and the pellets, containing most of the plastids, were resuspended in $18 \mathrm{ml}$ of grinding medium with minimal use of a Whirlimixer (Fison Scientific Apparatus Loughborough, Leicestershire, England). Clumps were removed from the suspension by filtration through Miracloth. For further purification of plastids, $4 \mathrm{ml}$ of the suspension was layered onto $30 \mathrm{ml}$ of cushion medium (same as grinding medium, but tricine concentration halved and sucrose concentration doubled) in each of 4 tubes and centrifuged for 10 minutes at $2500 \mathrm{rpm}$ (1020, maximum, R.C.F.) in a Sorvall HB-4 swinging bucket rotor. Again, the supernatant was discarded and the pellets, containing the plastids and now virtually no particles smaller than 2 to $3 \mu \mathrm{m}$ in

Abbreviations: SDS - sodium dodecyl sulfate, CPI - Chlorophyll-protein complex I, CPII - chlorophyll-protein complex II 
diameter other than starch, were resuspended in $3 \mathrm{ml}$ of cushion medium. After storage overnight at $4^{\circ} \mathrm{C}$ the plastids were subjected to hypotonic shock by the addition of $27 \mathrm{ml}$ of shocking medium $\left(4 \mathrm{mM} \mathrm{MgCl}_{2}, 5 \mathrm{mM} \mathrm{Ca}\right.$ $\left(\mathrm{NO}_{3}\right)_{2}$ and $\left.10 \mathrm{mM} \mathrm{KCl}\right)$.

The suspension was divided into two equal portions, centrifuged for 20 minutes at 20,000 rpm $(48,000$, maximum R.C.F.), and the supernatants were discarded. The pellet from one portion was resuspended with $2.5 \mathrm{ml}$ (chloroplast membranes) or $1.2 \mathrm{ml}$ (etioplast membranes) of solubilization buffer $(30 \mathrm{mM}$ sodium borate- $\mathrm{HCl}$ buffer, $\mathrm{pH} 8.9,5 \mathrm{M}$ urea, $1 \%$ SDS) and centrifuged for one-half hour at $38,000 \mathrm{rpm}(140,000$ maximum R.C.F.) in a Spinco 50.1 rotor. The supernatant supplied samples for electrophoresis, which was conducted promptly. The other portion of membranes was extracted and washed twice with $80 \%$ acetone. These acetone extracted membranes were then resuspended in $20 \mathrm{ml}$ of $4 \mathrm{mM}$ mercaptoethanol and pelleted by centrifugation for 20 minutes at $20,000 \mathrm{rpm}$. The pellet was resuspended in solubilization buffer and the solution was centrifuged at $38,000 \mathrm{rpm}$ as above. Thereafter, the supernatant was made to $2 \%(\mathrm{v} / \mathrm{v})$ mercaptoethanol, heated in a boiling water-bath for ca. 2 minutes, and provided samples for the electrophoresis of acetone extracted, chemically reduced membrane polypeptides.

\subsection{Electrophoretic Procedures}

Two different slab gel electrophoretic systems with discontinuous, alkaline buffers were employed. The first is hereafter called uniform gel system, because the separating gel was uniform in polyacrylamide concentration, while the second is called gradient gel system, because the separating gel contained a polyacrylamide concentration graient.

In the uniform system the acrylamide to N, N'. methylenebisacrylamide ratio was $19: 1$, and the polyacrylamide concentration of the separating gel, stacking gel and well-former gel was 10,6 and 10\% respectively. These gels contained urea to a final concentration of $5 \mathrm{M}$. The gels were cast in Ortec cuvettes (No. 4214). Electrophoresis was performed at $15^{\circ} \mathrm{C}$ for $6 \mathrm{hrs}$ at a constant current of $60 \mathrm{~mA}$. The buffers employed were those described by MACHOLD (13). The gradient system has been described by CHUA and BENNOUN (3). The stacking gel was $2-3 \mathrm{~cm}$ and the separating gel was $15-16 \mathrm{~cm}$ long. The slabs were run at $12^{\circ} \mathrm{C}$ for $8 \mathrm{hrs}$ at a constant current of $17.5 \mathrm{~mA}$.

After electrophoresis all slabs were washed for $2-5 \mathrm{hrs}$ in methanol-acetic acid-water $(5: 1: 5$ by volume) and stained for $2-5 \mathrm{hrs}$ in $0.05 \%$ Coomassie brilliant blue G-250 dissolved in the above mixture. Destaining was performed in $7 \%$ acetic acid. Molecular weights were determined using the protein standards noted earlier (13).

\section{RESULTS}

On polyacrylamide gels containing SDS, chloroplast lamellae solubilized appropriately with SDS yeild three chlorophyll containing bands (19). These bands are, starting from the lowest electrophoretic mobility, the chlorophyll-protein complex I (CPI), the chlorophyll-protein complex II (CPII) and chlorophyll in SDS micelles. These chlorophyll-containing bands were also found in the present analyses of barley chloroplast membranes in both the uniform and gradient gel systems. Thus the bands labeled CPI and CPII in Fig. IA, 2A and 4A were green prior to staining with Coomassie blue. Protein bands corresponding in position to $\mathrm{CPI}$ and $\mathrm{CPII}$ were not present in the etioplast patterns (Fig. 1A, $2 \mathrm{~A}$ and $4 \mathrm{~A}$ ).

When the chloroplast membranes are extracted with acetone prior to solubilization with SDS, protein bands are no longer obtained at the exact location of CPI and CPII. It has been shown by isolation of CPI and CPII and subsequent electrophoresis, that the bands $I\left(=B_{1}\right)$ and IIa, $b$ (Fig. IB and 2B) or II (Fig. 4B) are proteins contained in CPI and CPII respectively $(4,8$, $14,16)$. The apparent molecular weight of the band I from barley was determined by co-electrophoresis in the uniform gel system to be the same as that of band I from Vicia faba previously determined (13) at 69,400. For Chlamydomonas reinhardtii a value of 66,000 (poly- 


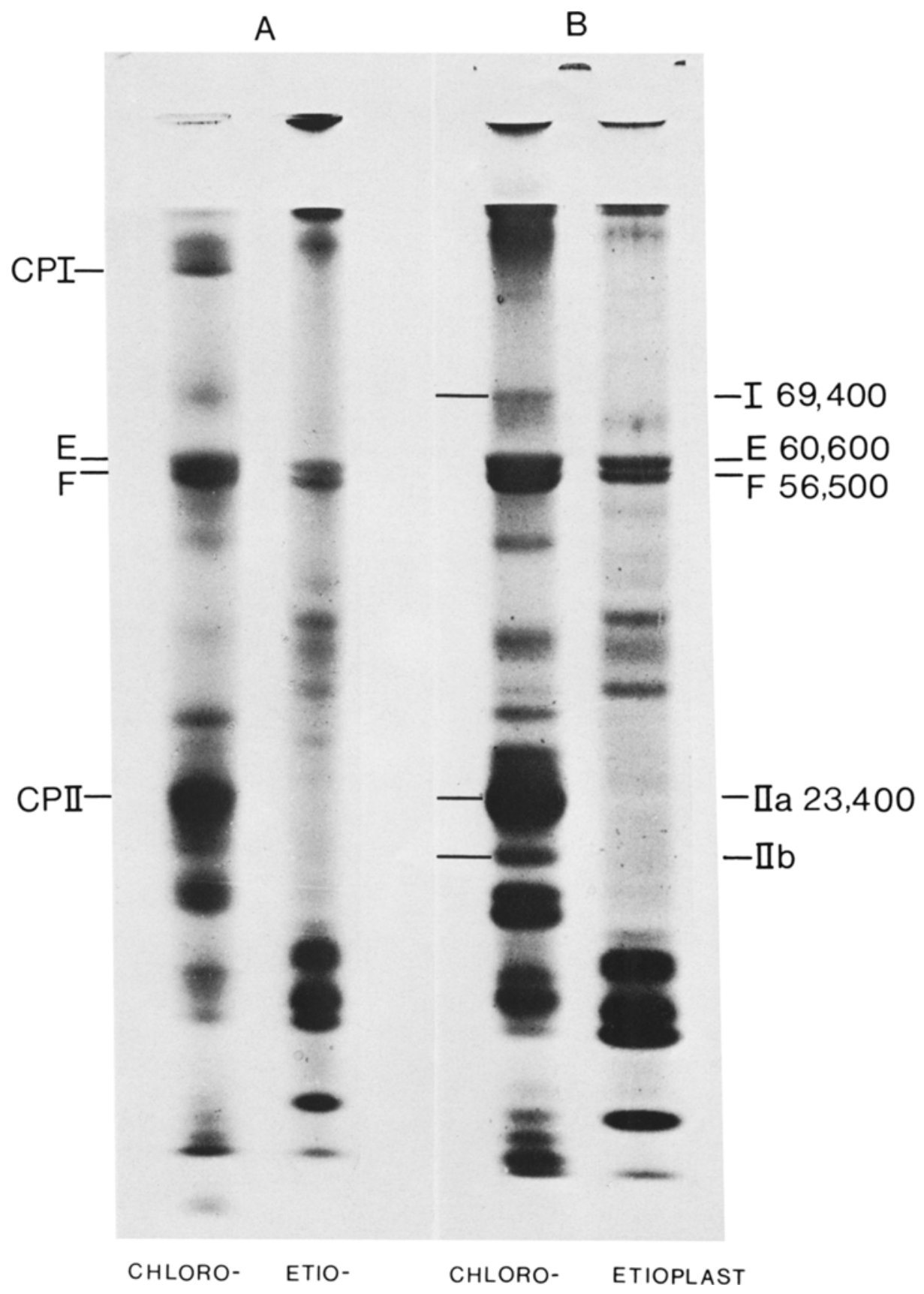

Figure 1. Separation of chloroplast and etioplast membrane proteins in the uniform gel system. A. Membranes disintegrated in their native state with SDS. B. Membranes extracted with acetone prior to SDS-solubilization and reduction with mercapto ethanol.

peptide 2), and for spinach and chinese cabbage a value of 64,000 has been reported (4). Acetone extraction of CPI gives in addition to band I, aggregates that remain at or close to the top of the gel $(4,14)$. Aggregates at that position were present in all etioplast patterns in this study. 


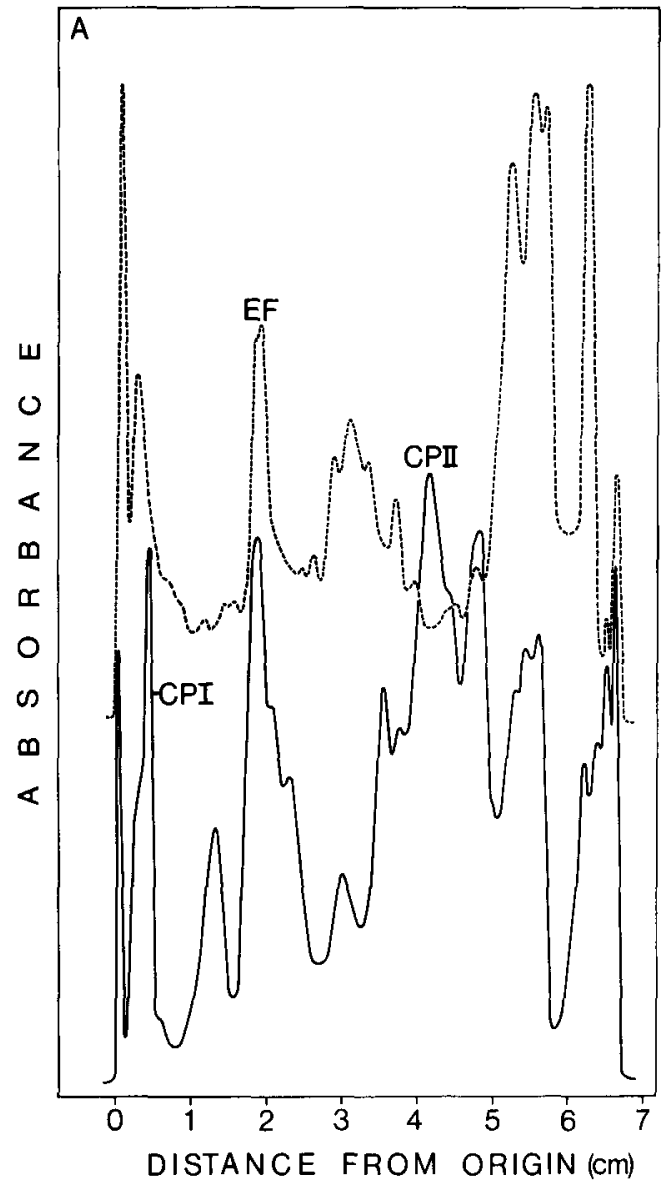

Figure 2. Densitometer tracings of gels depicted in Figure 1. A. Membranes disintegrated in their native state with SDS. B. Membranes extracted with acetone

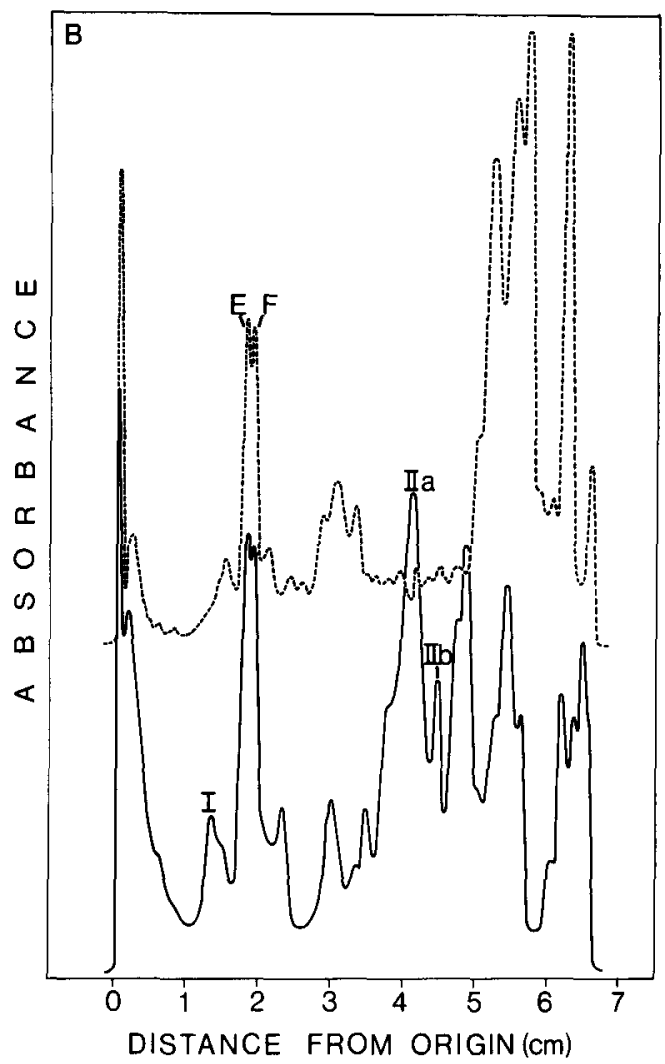

prior to SDS-solubilization and reduction with mercaptoethanol. Solid lines: chloroplast membranes. Broken lines: etioplast membranes.
The electrophoretic patterns of the etioplast membranes lack the protein bands I, IIa, IIb and II. The most striking common feature of all the etioplast patterns is the sparsity of proteins with electrophoretic mobility between that of the $E$ and $F$ bands and a group of heavily stained bands near the bottom of the gels, while chloroplast patterns all show a number of intensely stained bands in addition to those already discussed in the corresponding region. Among the few bands of this region in the etioplast pattern a very distinct doublet (arrows in Fig. 3B, 4A and 4B) occurs, but only in the gradient gel system. This doublet is absent or reduced in the comparable patterns of chloroplast membranes. A direct experiment showed that when $5 \mathrm{M}$ urea, which is present in the uniform gels is included in the gradient gels, the doublet is not found in patterns of etioplast membrane polypeptides (8).

The two bands, marked $\mathrm{E}$ and $\mathrm{F}$ in the figures were present in all chloroplast and etioplast membrane patterns and did not change mobility after acetone extraction and chemical reduction. Thus they serve as useful markers in the patterns. Bands in Vicia faba with identical electrophoretic mobility have been tentatively identified to be subunits of the coupling factor $(14,20)$.

In the region of highest electrophoretic mobility drastic differences between the band patterns obtained with etioplast and chloroplast 
membranes, respectively, are apparent regardless of the system employed, but a detailed homology cannot be established from the present comparison.

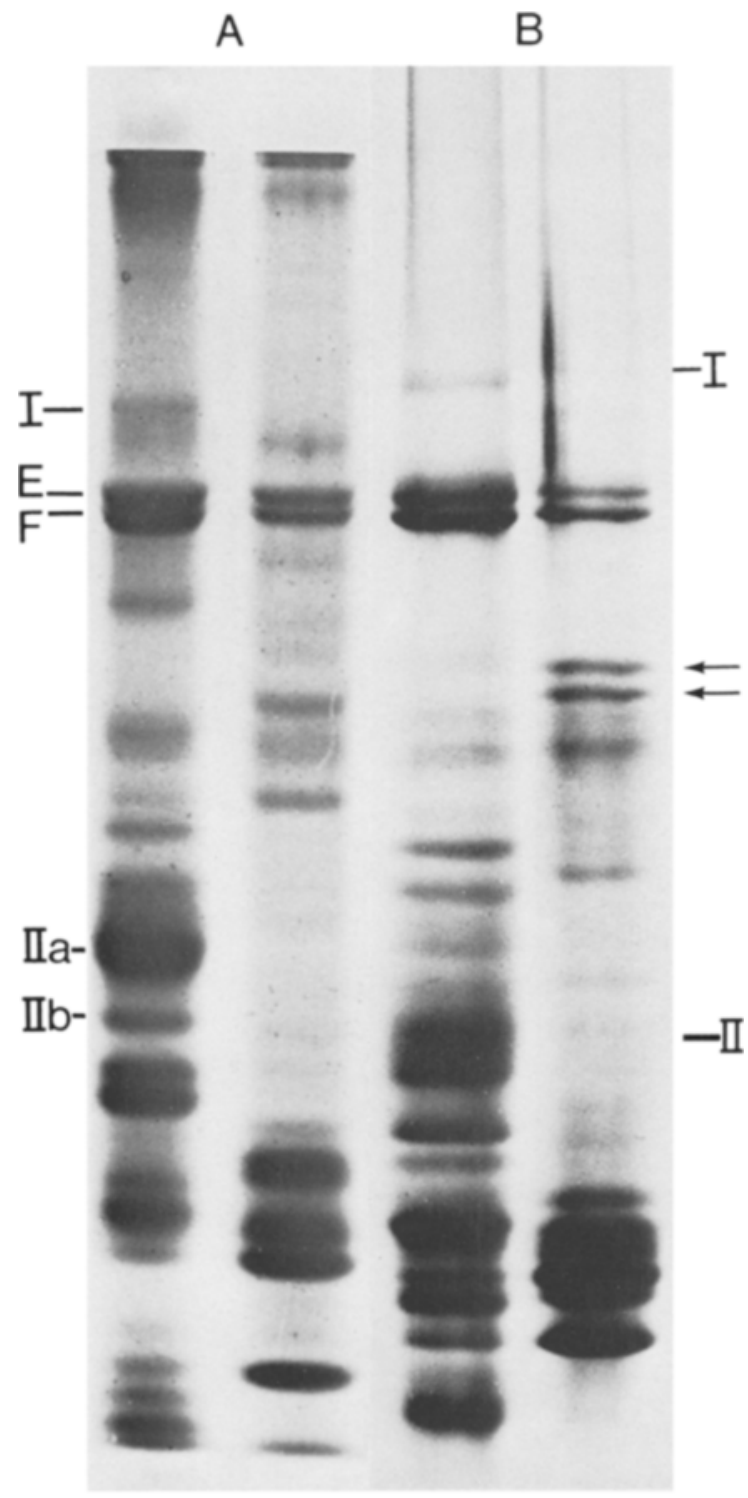

CHLORO- ETIO- CHLORO- ETIOPLAST

Figure 3. Electrophoretograms of chloroplast and etioplast membranes extracted with acetone prior to SDS solubilization and reduction with mercaptoethanol. A. Separation in the uniform gel system. B. Separation in the gradient gel system.

\section{DISCUSSION}

The results of this study can be compared with the work of NIELSEN (17) who used phenol-acetic acid-8M urea for membrane solubilization and electrophoretic analysis of the polypeptides on acid-soaked polyacrylamide gels. He found that barley etioplast and chloroplast membranes differ in protein composition, and that during recovery from etiolation and concomitant greening in the light, five new bands appeared or increased in intensity in the patterns, while certain characteristic bands of the etioplast pattern decreased in intensity. With the reasonable assumption of at least moderate correspondence between NIELSEN's and the present results, one can relate the polypeptides arising or increasing during greening in the following way: NIELSEN's high molecular weight band B corresponds to the 69,400 apparent molecular weight band 1 originating from the chlorophyll-protein complex I, NIELSEN's I. $J$ and $K$ bands correspond to some or all of the bands in the vicinity of the chlorophyll-protein complex II. It is in this region of the gels that the most prominent differences between the chloroplast and the etioplast patterns are found, regardless of the membrane solubilization procedure and the electrophoretic system employed.

Our failure to detect the protein band I in etioplast membranes can be taken as evidence for its absence. Caution is in order, however: aggregated protein found regularly at the top of gels following the electrophoresis of etioplast membrane polypeptides could well contain band I protein, thus preventing its detection $i$ the gels.

The detection of bands tentatively identified as subunits of coupling factor from etioplast membranes complements the earlier finding (12), that particles the size of coupling factor as well as coupling factor activity are associated with etioplast membranes of maize.

A particular doublet (arrows in Fig. $3 \mathrm{~B}$ and Fig 4A and B) is characteristic for the etioplast but not the chloroplast membrane polypeptide patterns obtained with the gradient gel system which lacks urea. As noted earlier, the inclusion of $5 \mathrm{M}$ urea in the gels of the gradient gel 


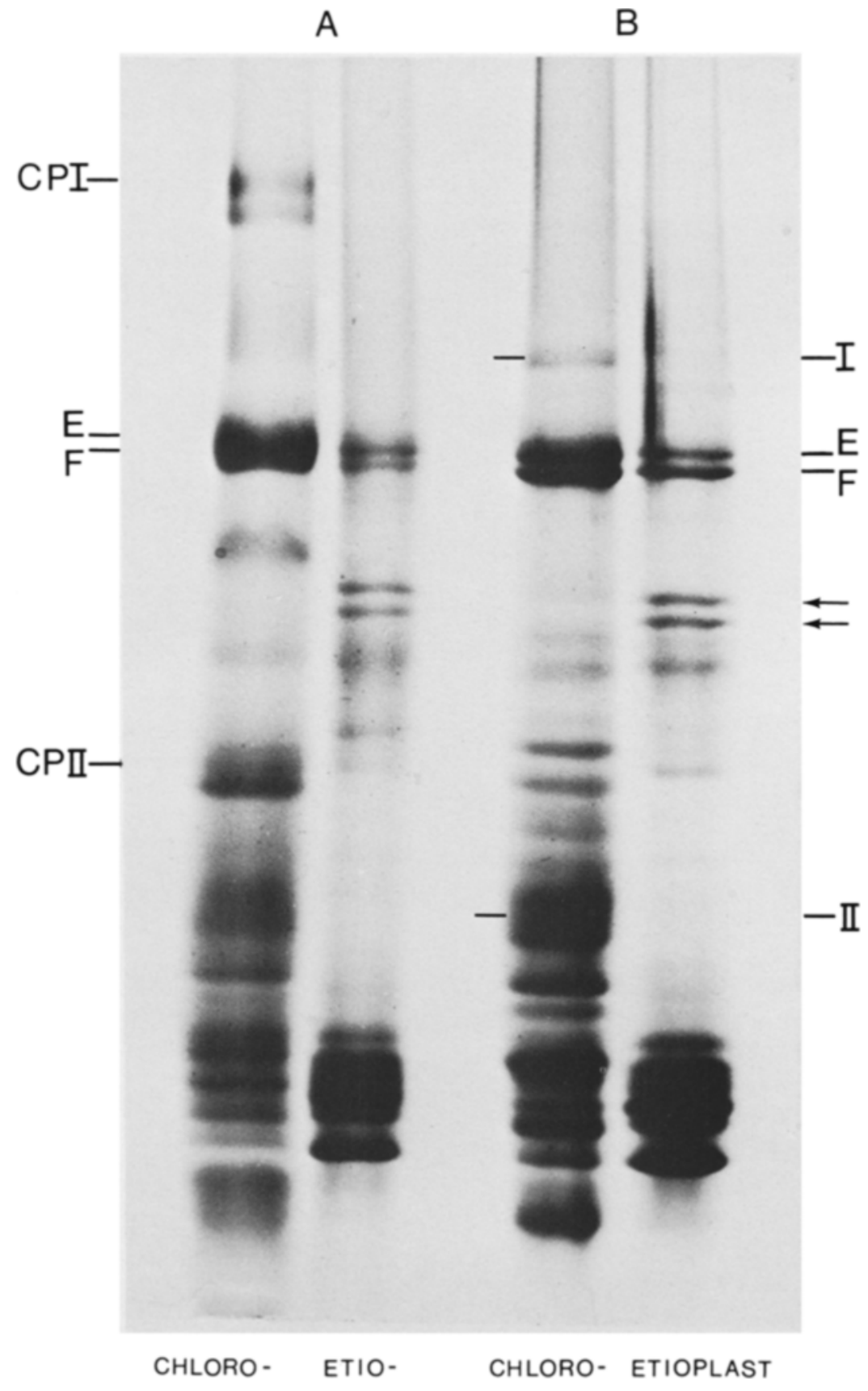

Figure 4. Separation of chloroplast and etioplast membrane proteins in the gradient gel system. A. Membranes disintegrated in their native state with SDS. B. Membranes extracted with acetone prior to SDS-solubilization and reduction with mercaptoethanol. 
system (8) or the uniform gel system (Fig. 1,2 and $3 \mathrm{~A}$ ) results in patterns of etioplast membrane polypeptides which lack the doublet. Clearly, urea alters the electrophoretic characteristics of the doublet polypeptides in SDS. Since $5 \mathrm{M}$ urea was present during solubilization of the polypeptides and their application to the gels in all the cases under discussion, the fact that the doublet was detected after electrophoresis on gels lacking urea indicates that the effect of urea on the doublet polypeptides is reversible. Therefore it is likely that urea induces reversible conformational changes in the doublet polypeptides, indicating that they are not fully denatured by SDS or by acetone extraction and chemical reduction.

The doublet polypeptides have been detected with the gradient gel system in the chloroplast membranes of all light-grown chloroplast mutants of barley from the Copenhhagen stock collection examined so far (8). Furthermore, the doublet decreases in intensity in membrane protein patterns as greening of dark-grown, wild type barley proceeds in light (8). Accordingly, the doublet polypeptides are associated with blocked chloroplast development both where the block is genetic and where it is environmental.

Several investigators $(5,6,7,17)$ have provided evidence, that at early stages of greening newly formed membrane proteins and chlorophyll are inserted into existing membranes, while at later stages synthesis of all membrane components takes place. Others have suggested that qualitatively all polypeptides are present prior to greeening and that functional photosynthetic membranes can be formed by reorganization as chlorophyll accumulates (10). Only the determination of the primary structure of the various polypeptides can clarify fully the mode in which photosynthetic membranes are constructed. This is also required for a decision as to whether or not the bands which are present in the etioplast pattern, but decrease in intensity after greening, serve as precursors or subunits of chloroplast specific membrane proteins.

\section{ACKNOWLEDGEMENTS}

We thank Professor D. v. WetTSTEIN for valuable discussions. Miss S. PLACING provided skilful technical assistance. Financial support was provided in part by USPHS, National Institutes of Health (GM-22051) and EEC Contract 029-76-ES DK solar energy program.

\section{REFERENCES}

1. Anderson, J. M. \& R. P. Levine. Membrane polypeptides of some higher plant chloroplasts. Biochim.Biophys.Acta 333: 378-387 (1974)

2. BECK, D. P. \& R. P. LEVINE. Synthesis of chloroplast menbrane polypeptides during synchronous growth of Chlamydomonas reinhardtii. J. Cell Biol.63: 759-772 (1974)

3. Chua, N. -H. \& P. Bennoun. Thylakoid membrane polypeptides of Chlamydomonas reinhardtii: Wild-type and mutant strains deficient in photosystem II reaction center. Proc. Nat. Acad. Sci. USA 72: 2175-2179(1975)

4. Chua, N. -H, K. Matlin \& P. Bennoun. A. chlorophyll-protein complex lacking in photosystem I mutants of Chlamydomonas reinhardtii. J. Cell Biol.67: 361-377 (1975)

5. CoвB, A. H. \& A. R. Wellburn. Developmental changes in the levels of SDS-extractable polypeptides during plastid morphogenesis. Planta 114: $131-142$ (1973)

6. Eytan, G. \& I. OHAD. Biogenesis of chloroplast membranes. VI. Cooperation between cytoplasmic and chloroplast ribosomes in the synthesis of photosynthetic lamellar proteins during the greening process in a mutant of Chlamydomonas reinhardi $\mathrm{Y}$-1. J.Biol.Chem.245: 4297-4307 (1970)

7. НоOвER, J. K.: A major polypeptide of chloroplast membranes of Chlamydomonas reinhardi. $\mathrm{J}$. Cell Biol. 52: 84-96 (1972)

8. HøYER-HANSEN, G.: unpublished results

9. Kannangara, C. G. \& C. J. Jensen.: Biotin carboxyl carrier protein in barley chloroplast membranes. Eur. J. Biochem. 54: 25-30 (1975)

10. Lagoutte, B. \& J. Duranton.: The action of light at the structural proteins level on etiolated plastids from Zea mays $L$. FEBS Letters 28: 333-336 (1972)

11. Liebers, H. \& B. Parthier. Synthese der Lamellarproteine in Chloroplasten ergrünnender Euglena gracilis. Biochem. Physiol. Pflanzen 165: 517-530(1974)

12. Lockshin, A., R. H. FALK, L. Bogorad \& C. L. F. Woodcock: A coupling factor for photosynthetic phosphorylation from plastids of light- and dark-grown maize. Biochim.Biophys. Acta 226: 336-382 (1971)

13. MACHOLD, O.: Molekulargewichtsbestimmung von Chloroplasten-Proteinen durch Dodecylsulfat-Gelelektroforese. Biochem. Physiol. Pflanzen 166: 149-162 (1974) 
14. MAChold, O.: On the molecular nature of chloroplast thylakoid membranes. Biochim.Biophys.Acta 382: 494-505 (1975)

15. Machold, O.\& G. Høyer-Hansen.: Polypeptide composition of thylakoids from viridis and xantha mutants in barley. Carlsberg Res.Commun. 41: 359-366 (1976)

16. Machold, O., A. Meister, H. Sagromsky, G. HøYer-HANSEN \& D.v. WetTSTEIN:: Composition of photosynthetic membranes of wild-type barley and chlorophyll b-less mutants. Photosynthetica in press

17. NiELSEN, N. C.: Electrophoretic characterization of membrane proteins during chloroplast development in barley. Eur.J.Biochem. 50: 611-623 (1975)
18. Phung Nhu Hung, S., R. Remy \& A. Moyse.: Cytochromes and lamellar proteins of greening barley etioplasts. In: Proc. 2nd. Int. Congr. Photosynthesis. G. Forti, M. Avron \& B. A. Melandri, eds. Junk, The Hague pp.2407-2415 (1971)

19. Thornber, J. P., J. C. Stewart, M. W. C. Hatton \& J. L. Balley.: Studies on the nature of chloroplast lamellae II. Chemical composition and further physical properties of two chlorophyll-protein complexes. Biochemistry 6: 2006-2014 (1967)

20. SUss, K. H.: Identification of chloroplast thylakoid membrane polypeptides: Coupling factor of photophosphorylation $\left(\mathrm{CF}_{1}\right)$ and cytochrome-f. FEBS Letters 70: 191-196 (1976) 